\title{
Application of the approaches Top-down and Bottom-up for the construction of a Risk Mapping of an insurance company
}

\author{
El Arif Fatima Zahra ${ }^{1}$, Hinti Said ${ }^{2}$ \\ ${ }^{I}$ PhD student - Department of Economics and Management, Center of Doctoral Studies, Faculty of Economic \\ Sciences, University Mohammed V-Souissi, Rabat, Morocco \\ ${ }^{2}$ Professor Authority - Department of Economics and Management, Faculty of Economic Sciences. \\ University Mohammed V-Souissi, Rabat, Morocco.
}

\begin{abstract}
There are two main possible approaches for the construction of a risk mapping. The first one consists to identify the risks of the company, and the second is based on a census of risks by the Executive Committee. These two approaches are complementary.

In the top-down approach, the major risks are identified by the members of the Executive Committee, with regard to the strategy followed by the insurance company. The Risks are then attached to the process of the activity. In the bottom-up approach, the census of the processes of the company establishes the starting point of the process.

This article aims to present the outline of the two approaches, Top-Down and Bottom-Up, and apply them to risk management in insurance. The idea is to define a methodology to assess the risks associated with different processes, and rank them in order of priority in a risk mapping.
\end{abstract}

Keywords : Risks, Top-Down, Bottom-Up, Risk mapping, Insurance company.

\section{Introduction :}

The Top-down and Bottom-Up approaches are processes allowing to order stages for the realization of a project. The Bottom-up approach share of basic elements to go to the set, and the Top-down approach share of the set to go to the details. Both approaches are often complementary.

In our case, In the top-down approach, the major risks are identified by the members of the Executive Committee, with regard to the strategy followed by the insurance company. Risks are then attached to the process of the activity. Finally, risks are analyzed in the form of a matrix of criticality (frequency x severity) allowing a classification in order of priority for their treatment.

In the bottom-up approach, the census of the processes of the company establishes the starting point of the process. The level of detail, should be chosen so as to allow identification of the most significant process. This choice determines the hierarchical level of contact to meet to gather the appropriate information.

\section{II.1. "Top down" approach}

\section{Overview Of Approaches}

This approach consists of three main steps:

II.1.1. First step: risk analysis

In this step, the risk is addressed in an overall vision of the company. The approach is to identify the major risks by members of the Executive Committee. Thus, the hazards are identified under the strategy followed by the company. Another approach is to identify risks by stakeholders (employees, shareholders, customers, etc..), to identify threats which weigh on the company. The latter approach has been tested, but it does not, however, proven operational.

\section{II.1.2. Second step: the attachment of the risks with processes}

During this phase, it is to fill the dual purpose, of ensuring the consistency of identified risks with the entity's activities and exhaustiveness of the mapping.

Indeed, the risks identified at the Top-down approach, should be attached to the process of the activity.

\section{II.1.3. Third step: Evaluation and prioritization of risks}

The risk of an insurance company are analyzed in "Top-Down" approach with the head office, based on a two-dimensional graph (frequency / impact) in the form of matrix of criticality. The purpose of such an approach is to schematize the risk profile specific to the company risks, and to determine a priority of the major risks for their treatment. 
The levels of criticality in impact (potential loss in value units) may correspond to the thresholds in the context of the capital management (those of the parent company and those of the subsidiary), and through reinsurance (reinsurance of catastrophic events, reinsurance by claim).

The levels of criticality frequency (number of occurrences of a possible risk in a year), may be low, medium, high and some (that is say with some occurrence several times a year ).

The matrix of criticality can be represented in three versions: the raw risks, the accepted residual risks, and the real residual risks.

The approach is to ask every direction, to bring out half a score of major operational risks. The analysis of each of these risks by causes, control devices, and associated consequences, will estimate the parameters of risk quantification, and conduct an assessment of every risk. This approach is called Self Risk Assessment.

This so-called " Top-down " approach, allows us to obtain a first-time visibility into key risks facing the company. It also constitutes, an important vehicle information and awareness of the issues of operational risk ;

\section{II.2. Approach "Bottom-up"}

This approach also has three main steps :

\section{II.2.1. First step: the identification of the processes}

The census of the processes of the company establishes the starting point of this approach. A level of appropriate detail must be chosen according to the objectives of the mapping. This level should be enough fine, to identify appropriately the significant risks, but should not lead to list all sub-processes of the company. This choice allows then to determines the hierarchical level of contact to meet in order to collect information. Once the context of this approach was reminded respondents, the interview can take place in two distinct ways. It can be based on a questionnaire or take place in an open, allowing greater freedom in the expression of the vision process, and risks from operational.

The information gathered during this stage are then classified, to establish a classification of major processes. They are the basis for the establishment of the risk mapping, and can be classified into three main categories. Processes related to daily production (business processes), those relating to activities to the proper functioning of the insurance company (support processes), and those concerning the activities of management (management processes).

\section{II.2.2. Second step: identification of risks}

An initial risk identification, is performed during interviews with operational.

As of the census process, the description of risks can be done either on the basis of a questionnaire or openly, thus facilitating the identification of risks.

This first identification is built jointly, by the management of operational activity, and the teams in charge of mapping.

The census of the risks, being realized from various activities, it seems important to identify also the risk bound to the interrelations between these activities. It is only when this is achieved, that these risks can be classified. Several options are then available. The company can make the choice of a specific typology to the company, depending on the area of activity and objectives established for the approach.

\section{II.2.3. Third step: Evaluation and prioritization of risks}

Before embarking on this step, it is necessary to define a number of principles, such as methods of risk assessment. They are different, depending on whether it is a question of strategy, or business case types / risk. In summary, the evaluation may be either qualitative and be established on the basis of reports from the internal audit or expert advice, or semi-quantitative and based on a scoring system torque frequency / impact, or quantitative when a number of probable loss is associated with a risk.

The approach by risk mapping called "Bottom -up", is therefore to analyze a comprehensive and systematic operational risks, and controls associated with each process identified. It is a major tool for controlling the operational risk management, internal auditors and operational themselves.

This approach is based on two elements:

_ Find an appropriate level of granularity. Too fine mesh involve too heavy construction, and mapping result would be unmanageable daily. On the contrary, a too large mesh does not allow the control of operational risk.

_ Make sure of the implication of the actors of operational management in the development of the mapping. Process owners and controls, internal auditors, managers and risk managers, should be involved in the construction at first, then update the tool a second time [Fig. 1].

\section{II.3. Advantages, disadvantages, pitfalls}

The "bottom-up" method has advantages in 3 levels : 
- The approach by processes provides a sound knowledge of the insurance company, and the results can then be used for other purposes, as part of a reorganization or the opportunity to a quality approach.

- The analysis in detail activities allows a comprehensive risk identification.

- Consultation with business to achieve the mapping provides a satisfactory involvement on their part.

However, it is a time consuming process, in so far as it requires the holding of numerous conversations and the collection of mass information. Moreover, it can be costly in terms of skills and systems because the data collection of data often requires the use of appropriate tools.

As for the "Top-down" approach, it allows a lighter implementation because the necessary maintenance are fewer, and do not require an analysis of the processes. The review of strategic risks, also allows to make sure of the more immediate consideration of the transverse or managerial processes, which may be more in adequacy with the expectations of the head office.

However, it has the disadvantage of being less precise, both in identifying risks in their quantification. In addition, operational not being associated, they may have difficulty in appropriating the approach [Fig. 2]..

Operational consider these two approaches as complementary, and that is why he recommends, wherever possible, combine them according to the resources and deadlines.

Indeed, these two approaches, not only do not opposed, but are complementary. They can be conducted either sequentially or simultaneously, the question of choice may arise when starting the construction of a mapping.

\section{III.1. Methodology of risk assessment}

\section{Methodology :}

Risk assessment is one of the most difficult steps, and it is not always possible to assess risks, simply because it is difficult to quantify. However, risk is generally measured in terms of probability of occurrence and severity (consequences).

However, it is advisable to make the difference between a raw risk, which measure the risk without any control, (lack of procedures, lack of internal controls, lack of computer system, etc..), And a residual risk (or net risk), which measures the risk after implementation of the elements of control (internal control, financial coverage, risk transfer, etc..).

It is also in this sense, that we can understand the value of an internal control system, which will contribute to the reduction of the likelihood of the risk occurring.

For a good risk assessment, it is necessary to know how to appreciate the risk : by frequency levels (very likely, likely, unlikely or very unlikely), or according to a financial assessment of the impacts (what is the estimated cost of the occurrence of risk?). The evaluation of a risk, consists to provide defensible information on the frequency and impacts of risk.

The assessment should be qualitative before being quantitative. However, this assessment is generally insufficient and must be complemented by an assessment of the impact and frequency of occurrence (its probability). Indeed, the raw risk can be summarized by the following equation:

Raw risk $=$ Predictable impact $x$ Frequency of occurrence

It turns out, so commonly accepted, that the assessment of raw and residual risks is the responsibility of the operational, which apprehend more easily impacts. However, this estimate must be a confrontation with the person in charge of mapping to "validate" the hypotheses in terms of impact and frequency.

Assess the frequency components, is also a challenge for the development of cartography. To achieve this, it is necessary to identify all possible sources of information (discussions with operational, internal auditors, internal controllers, and external auditors, reading existing audit reports, sector documents, internal bases incidents, etc.)...

The idea, is to feed the arguments to confirm the assessment performed. This then serves as a basis for discussion with the operational to gather opinion on this frequency.

Otherwise, it is advisable to proceed to an arbitration to agree on a potential frequency. This iterative approach allows then to associate a frequency with to each couple process/ risk.

We find that it is appropriate to use a scale frequency, from 1 to 4 , from the least frequent to the most frequent, and of two levels of appreciation of this frequency: in time (the event happens every day, weekly, monthly, quarterly, 1, 5, 7, 20 or 100 years), and / or in volume (the event occurs in $1 \%$ of cases, $10 \%$ of cases, $0.1 \%$ cases, etc.), [Table. 1].

The time scale can be adapted according to the strategy of the insurance company, and the nature of risks which it incurs.

By convention, it is better to hold that: the more the risk is big, the greater the number should be. In addition, the proposed scale is a pair scale, in order to "take sides" and categorize the risk, what avoid risks "means" not allowing a meaningful analysis.

These evaluations are done in two phases:

- Risk taken into account assuming the passive business : raw risk ; 
- Risk taken into account with the measures already in place: residual risk

The [Table. 2].illustrates the evaluation process according to the possibilities of actual measurement of risk.

Finally, the responsibility for the risk assessment must be clearly arrested. Although, operational are the only owners of the risk, the responsibility for the evaluation can be however shared. To this end, the approach may rely on external expertises or techniques used in the departments of Risk Management, Audit and Internal Control.

\section{III.2. Methodology of measure of risk}

Risk components are both explicitly defined by the ISO definition of risk, and in the glossary of the Professional Standards Internal Audit, or under COSO 2: "the possibility of an event occurring that will have an impact on the achievement of the objectives. It confronts in terms of consequences and probability ».

This division is certainly different from that proposed in Solvency II, but it seems that it is closer to concerns of the operational.

\section{- In terms of consequences:}

- What are the consequences if the risk materializes? However, it is possible that it is as favorable or unfavorable situations. It seems like common sense to evacuate of the approach, the fact that, the emergence of risk is source of profit and opportunity for the insurance company.

Different consequences are divided into broad categories, namely:

- Financial loss (reduction in income, or increase of the costs);

- Civil and / or penal liability ;

- Legal and / or professional penalties ;

- Degradation of the image ;

Rather than consequences, we shall speak about impact.

\section{- In terms of probability:}

- What is the probability of the risk occurring ? It is the more or less possibility of underdoing the consequences of the relevant event, at any time or in time, then we talk about frequency of occurrence.

Only the combination of these two components allows to estimate reasonably the level of risk.

Finally, we must specify at which level of risk we are situated, raw risk or residual risk, as far as it is necessary to take into account the existence of elements designed precisely to reduce the consequences of its occurrence :

- The Raw risk measures the risk without any control : lack of procedures, lack of internal controls, lack of computer system ...

- The Residual risk or net risk measures the risk after implementation of control elements : internal control , financial coverage, risk transfer ...

The list of the identified and estimated risks represents then in the form of a " risk map " according to an axis "frequency" and an axis "potential impact".

\section{III.3. Level of Granularity}

We define the granularity, the level of detail which can construct a mapping. The definition of granularity is critical, because the more the level of detail is fine, and the more the corresponding work of identification of the risks is important. It therefore affect the development of mapping and its subsequent maintenance. Choosing the right level of granularity, is also important to calibrate the approach in the available ways, and in the desired schedule.

Thus, five additional levels of granularity, from the larger to the more particular, have been identified:

- Business : Casualty, Life, Assistance, Reinsurance ...;

-Area : for casualty, housing, car, aviation ...;

- Process: for individuals: subscription process, claims process, benefits process ... ;

- Operation : for the benefit process: registration, settlement of claims ...;

- Elementary task : for the operation claim : settlement, sending the check...

These levels are independent of the nature of the operations.

We must therefore agree to denote the median level "process" as the appropriate level of a map. Indeed, it is on the one hand the best compromise between the time spent in developing of mapping, and the degree of relevance of the vision of the risks. On the other hand, it is the level of balance allowing to make converge and to connect elements obtained from each of two main methods (Top Down and Bottom Up).

\section{Application And Discussion \\ IV.1. Approach for an insurance company \\ IV.1.1. Preliminaries: \\ - We take the example of a casualty company, by making a risk analysis considered as major, excluding financial risks. The presented evaluations are not specific to a particular company.}


- We recommend that this method be implemented with regular updates by the same service of the company (service Risk Management, Internal Audit, ...).

- This method should provide a common representation of the risks of an insurance company whatever is the nature of these risks. In particular, the thresholds used in the management "Core business" of the insurer, are included in the used scales, allowing a homogeneous and coherent calibration of the levels of risk (risk retention per event or per individual claim taken into account in the programs of reinsurance).

\section{IV.1.2. Scales:}

\section{- Potential Intensity:}

4 : Extreme and Unlimited (in the case of a subsidiary, it would jeopardize the financial position of the company). A threshold can be defined, according to stockholders' equity and to solvency of the concerned group.

3: Between a critical threshold (monetary amount or sinister image may result in the bankruptcy of the company ) to the edge of level 4 . This threshold is specific to each insurance company.

2: Between average threshold and critical threshold. The average corresponds to the maximal retention taken into account in the programs of reinsurance by event, ie a sustainable threshold but should only be done rarely or once every 10, 20 years or more, in liaison with the superior border of the level 2 of the frequency ( here, this border, equal to 5\%, corresponds to events cost equal to the average threshold, occurs approximately every 20 years).

1: Lower than the average threshold. At an intermediate level between the average threshold and the negligible, the maximum retention is set by the company for the conservation of reinsurance of individual claims.

\section{- Potential frequency (number of occurrences of risk per year):}

4 : Is carrying one or more times each year.

3: Can be achieved once in a year with high probability, pulling a frequency $>5 \%$.

2: Can be achieved once in a year in a rare way (between the tolerence threshold below $5 \%$ ).

1: In below a tolerance threshold.

For each risk, according to its raw potential intensity [or of its raw potential frequency] and of the optimal performance of its management, a transition from raw risk to residual risk according to the [Table. 3].

The optimal effect of the measures of Risk Management and internal control considered above, is in fact, more or less attenuated, depending on the quality of internal control. The hypothesis made consistently is that of an internal control of good but not optimal quality (note 2 on a scale of 0-3) for all the considered risks.

The actual performance of the management of each risk is evaluated using the [Table. 4]. Then, the residual risk is assessed by combining the raw risk with actual performance.

\section{IV.2. Construction of risk matrices}

The results are presented in three separate matrices:

- MATRIX Nº 1 : MATRIX OF CRITICALITY OF ORIGIN: RAW RISKS

(Hypothesis 1 : no reaction of the company)

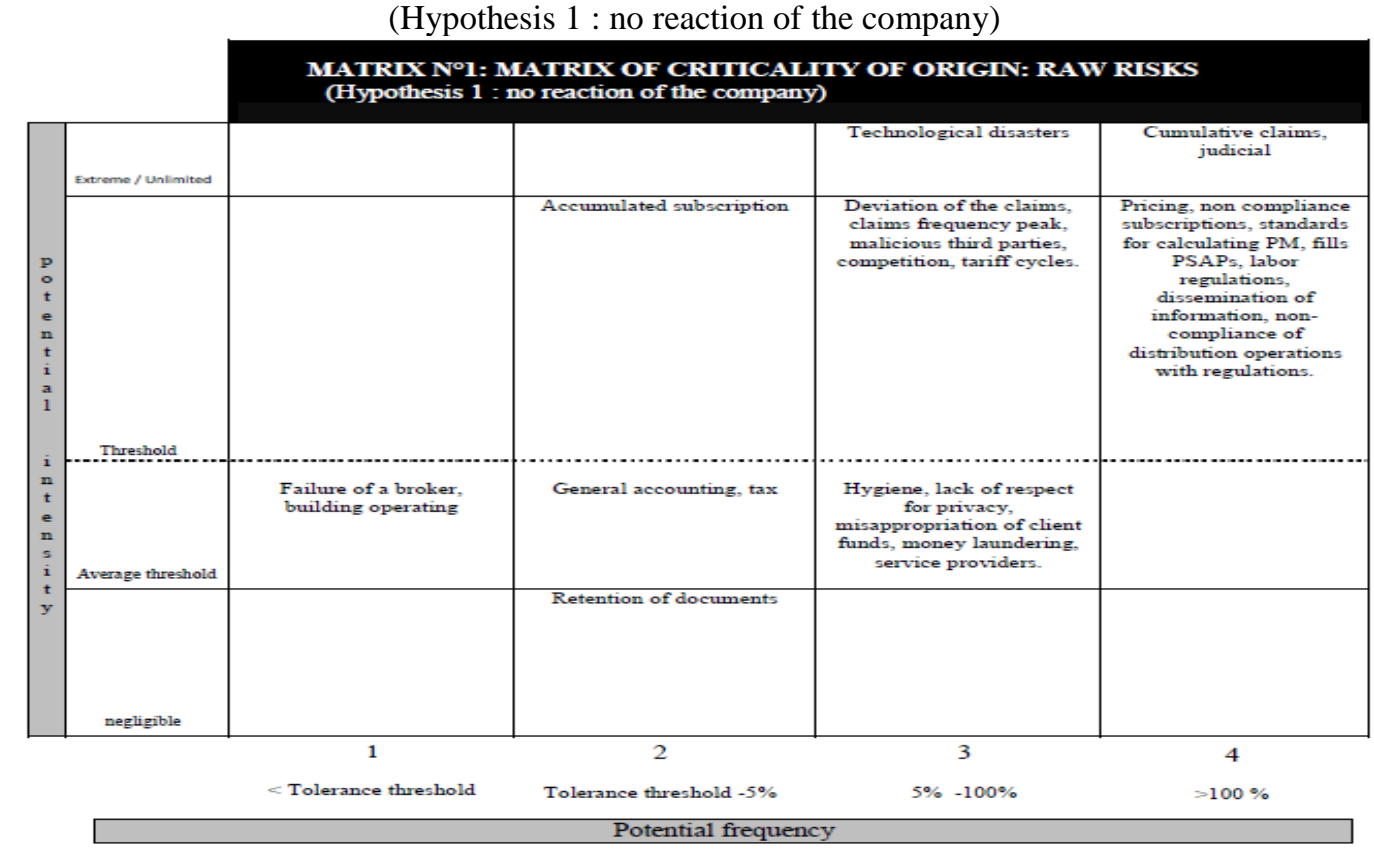


- MATRIX N²: MATRIX OF TARGET CRITICALITY: POSSIBLE AND DESIRED RESIDUAL RISKS

(Hypothesis 2 : good system of Risk Management and Optimal Internal control)

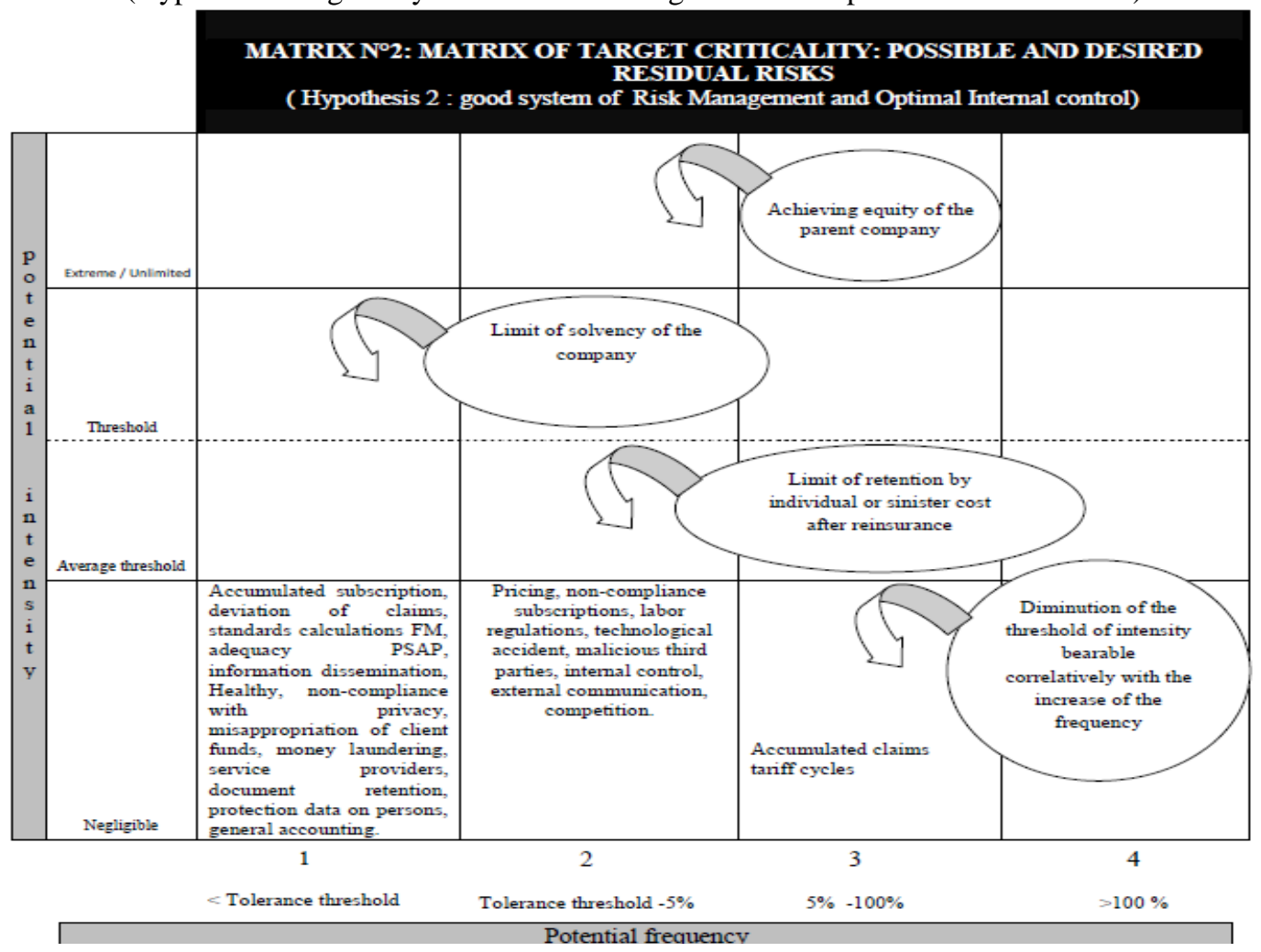

- MATRIX 3: MATRIX OF CRITICALITY IN PROGRESS: RESIDUAL RISKS ACHIEVED

(Hypothesis 3 : good system of Risk Management and good level of Internal Control)

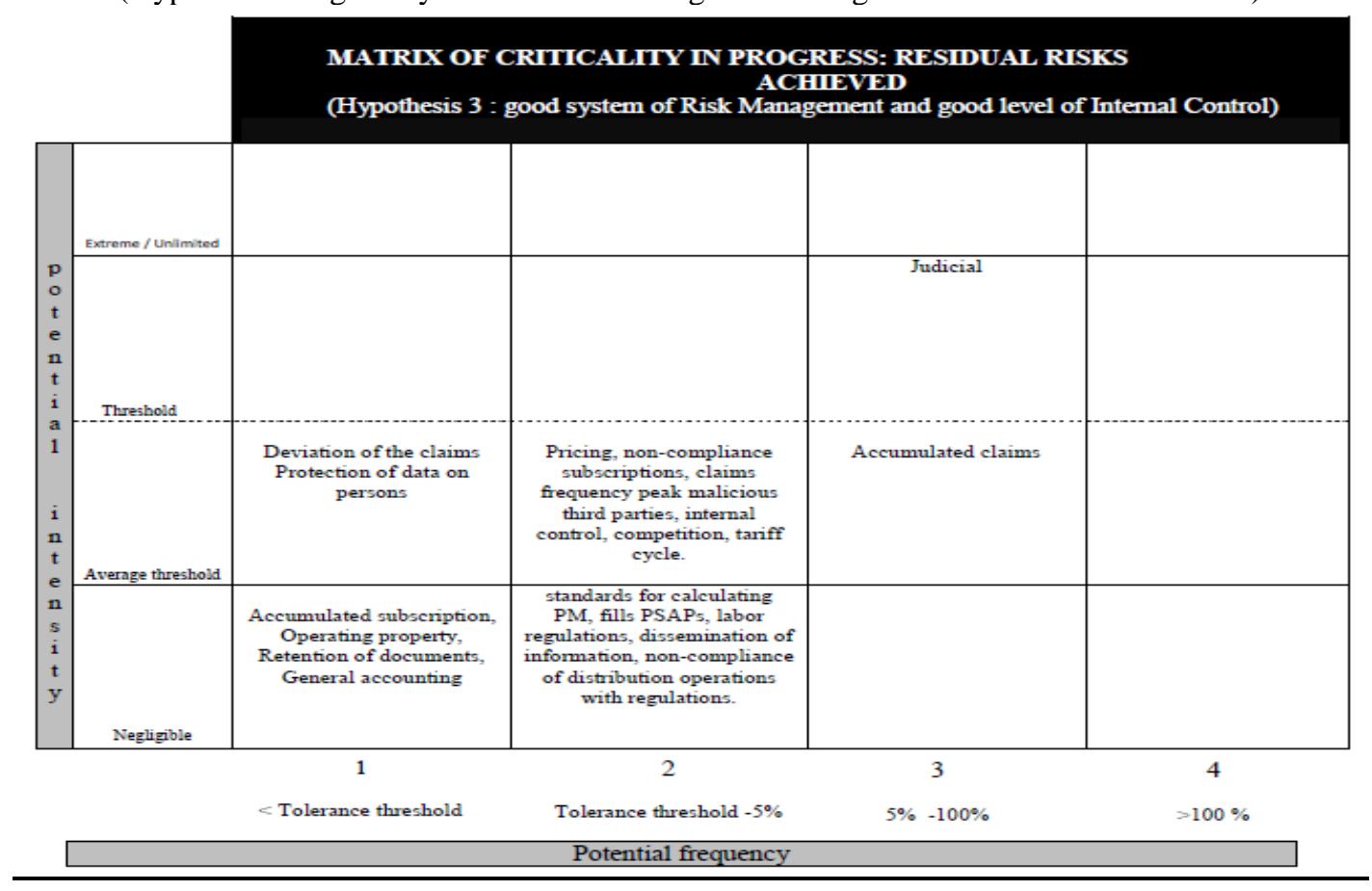

These presentations contains many hypotheses. The implementation of this method must be accompanied by an adaptation to the specific case of each insurance company, and consistent assessments on :

- The raw risks;

- The expected impacts of the risk management system on their reduction (residual risk targets);

- The quality of internal control procedures in place. 


\section{V.1. Figures}

\section{Figures And Tables}

Business
Area
Process
Elementary task

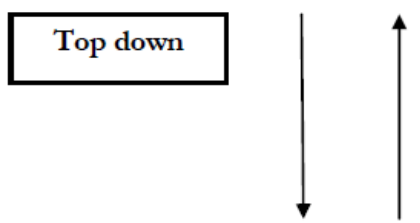

Bottom up

Fig1. Complementarity of the two approaches

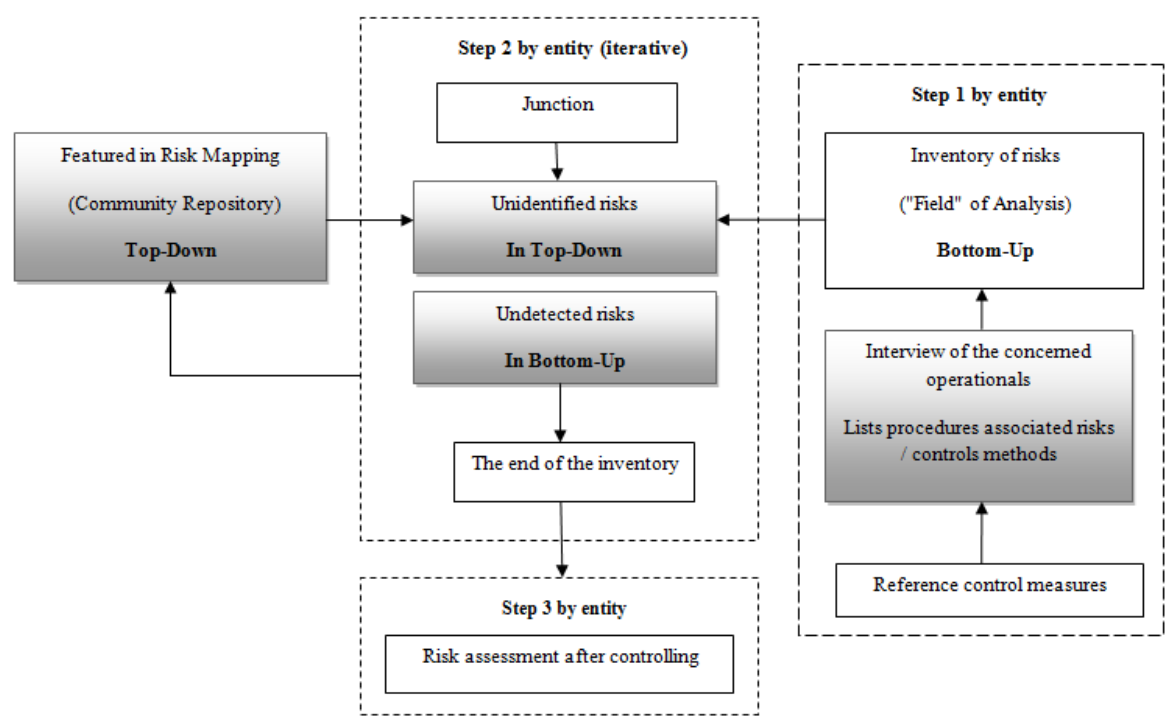

Fig 2. Application of Top Down and Bottom Up approach to the various entities

\section{V.2. Tables}

Table 1. Frequency range of risks in time and volume

\begin{tabular}{|l|c|c|c|c|}
\hline Level & $\mathbf{1}$ & $\mathbf{2}$ & $\mathbf{3}$ & $\mathbf{4}$ \\
\hline In time & Very unlikely & Unlikely & Likely & Very likely \\
\hline In volume & $>3$ years & $1-3$ years & 6 months -1 year & $<6$ months \\
\hline
\end{tabular}

Table 2. Evaluation process according to the possibilities of effective risk measurement

\begin{tabular}{|c|c|c|l|}
\hline $\begin{array}{c}\text { Estimation of : } \\
\text { of occurrence of the risk } \\
\text { (f) }\end{array}$ & Qualitative & $\begin{array}{c}\text { Semi quantitative } \\
\text { Null / Low / medium / } \\
\text { high } \\
\text { Or digital scale with an } \\
\text { even number of levels }\end{array}$ & $\begin{array}{l}\text { Average expected from } \\
\text { the nb of emergence in } \\
\text { the horizon of time } \\
\text { chosen (Basel II: f=Nxp) }\end{array}$ \\
$\begin{array}{c}\text { The potential impact in } \\
\text { terms of financial cost } \\
\text { («severity } »)\end{array}$ & $\begin{array}{l}\text { Amount on scale of } \\
\text { continuous value (ex: } \\
\text { million of } € \text { ) }\end{array}$ \\
\hline $\begin{array}{c}\text { The potential impact in } \\
\text { terms of image, } \\
\text { challenged leaders }\end{array}$ & $\begin{array}{c}\text { Description of the effets } \\
\text { including: possible } \\
\text { challenged of leaders }\end{array}$ & $\begin{array}{c}\text { Scale of gravity } \\
\text { according to objective } \\
\text { criteria, with an even } \\
\text { number of levels }\end{array}$ & $\begin{array}{l}\text { To define on a case by } \\
\text { case if possible (penalty: } \\
\text { see supra financial } \\
\text { impact.) }\end{array}$ \\
\hline
\end{tabular}


* - N: Expectation for the time horizon (1 year), of number of generative events of the risk.

- p: Probability that the risk will occur during an event.

- In many cases, one of these two characteristics, in particular P, are not estimable, and / or it is easier to make a direct estimation of the annual frequency.

Table 3. Evaluation of the performance with regard to the raw risk

\begin{tabular}{|c|c|c|c|c|}
\hline Performance/ Raw Risk & $\mathbf{4}$ & $\mathbf{3}$ & $\mathbf{2}$ & $\mathbf{3}$ \\
\hline $\mathbf{4}$ & 1 & 2 & 2 & 4 \\
\hline $\mathbf{3}$ & 1 & 1 & 1 & 3 \\
\hline $\mathbf{2}$ & 1 & 1 & 1 & 2 \\
\hline $\mathbf{1}$ & 1 & 1 & 1 & 1 \\
\hline
\end{tabular}

Table 4. Evaluation of the quality of the internal control with regard to the performance

\begin{tabular}{|c|c|c|c|c|}
\hline $\begin{array}{c}\text { Quality of IC/ } \\
\text { Target Performance }\end{array}$ & $\mathbf{4}$ & $\mathbf{3}$ & $\mathbf{2}$ \\
\hline $\mathbf{4}$ & 1 & 2 & 3 & 4 \\
\hline $\mathbf{3}$ & 1 & 1 & 2 & 3 \\
\hline $\mathbf{2}$ & 1 & 1 & 1 & 2 \\
\hline $\mathbf{1}$ & 1 & 1 & 1 & 1 \\
\hline
\end{tabular}

\section{Conclusion}

In a world of increasingly complex and unpredictable, the Executives of insurance companies understand well that the risk management guaranteed economic, information, strategic, structural or operational, more reliable and of better quality.

Although officials of the organizations have a vision and a comprehensive approach of the risks inherent in their activities, construct a risk map can only provide them new observational elements for better control and direct their objectives.

It is for this reason, that leaders must be convinced of the value of risk mapping, encourage and actively participate in its implementation .

Applications of risk mapping are numerous, and lead users to prefer this or that aspect of the results in order to redefine their priorities.

From the Board of Directors to the Head office, by way of the operationnal managers, risk managers , internal controllers and internal auditors, everyone can use mapping as a support for their own organization actions.

Any risk mapping should not be an end in itself, but a starting point for action. Simple in its principle but complex to develop, a mapping must first have the approval and support of all participants, so that the results reflect the reality of the organization and its risks.

\section{References :}

[1] Artzner, P., F. Delbaen, J. M. Eber et D. Heath, Coherent Measures of Risk, Mathematical Finance, $1999,9,203-228$.

[2] Augros J.C., Moreno M., Les dérivés financiers et d'assurance, Paris, Economica, 2002 ;

[3] Blayac T., Rousseau J.M., Nassim Oulmane, Introduction à la théorie de l'assurance, Dunod, 2001

[4] Coopers \& Lybrand, Le management des risques de l'entreprise, Cadre de Référence (COSO 2), Les Editions d'Organisation, 2002

[5] Coles S., Powell E., Bayesian methods in extreme value modelling : a review and new developments, Internat. Statist. Rev. 64, 1996, 119-36.

[6] El Arif F., Hinti S., Operational Risk Management in insurance through the process of Self Risk Assessment : Methodology of application », International Journal of Advanced Research, Volume 1, Issue 9, 2013, 646-656.

[7] Embrechts P., Klüppelberg C., Mikosch T., Modelling Extremal Events for Insurance and Finance, Springer Verlag, Berlin, 1997.

[8] Harlow, W.V.: Asset Allocation in a Down-Risk Framework", Financial Analysts Journal, 47, 1991, 28-40.

[9] HM Treasury. : The Orange Book, Management of Risk - Principles and Concepts. HMSO, 2004.

[10] Hosking, J.R., Wallis, J.R., Parameter and quantile estimation for the generalized pareto distribution, Technometrics 29, 1987, 33949.

[11] Hull, J.C., Risk Management and Financial institutions. Options, Futurs and Other Derivatives. New York, 2006.

[12] Thérond P.E., Contrôle de la solvabilité des compagnies d'assurance : évolutions récentes, Séminaire Gestion des risques et assurance, Hanoï, 2005.

[13] Thérond P.E., Planchet F., Provisions techniques et capital de solvabilité d'une compagnie d'assurance : méthodologie d'utilisation de Value-at-Risk, Assurances et gestion des risques 74 (4), 533-63 et in Proceedings of the 37th ASTIN Colloquium, Orlando, 2007.

[14] Thérond P.E., Girier G., Solvabilité 2 en construction, L’Argus de l'assurance, Hors-série de décembre, 2005. 